\title{
MODEL PENINGKATAN KOMITMEN ORGANISASI PADA PERGURUAN TINGGI SUWASTA (PTS) KOTA DAN KAPUPATEN SERANG UNTUK MENINGKAT KINERJA ORGANISASI SECARA BERKELAJUTAN
}

\author{
Suryaman \\ Universitas Serang Raya
}

\begin{abstract}
ABSTRAK
Komitmen organisasin pada perguruan tinggi berpengaruh terhadap kualitas dan daya dukung terhadap keberlanjutan suatu orgnasiasi, dalam hal ini banyak analisa yang dikembangkan untuk mengukur komitmen organisasi, namun tidak banyak yang membahas model komitmen organisasi itu sendiri terhadap keberlanjutan suatu organisasi yang menaungi sang dosen. Penelitian ini dilakukan sebagai upaya untuk mengukur komitmen organanisasi untuk mendukung keberlanjutan perguruan tinggi. Sebuah (PTS ), Model penilaian komitmen dosen dikembangkan untuk melihat apakah komitmen dosen berpengaruh terhadap keberlanjutan perguruan tinggi. Metode penelitian yang digunakan adalah deskriptif dan verifikatif sampel data sebanyak 275 dosen PTS Kota dan Kabupaten, Aplikasi Structural Equation Model (SEM) digunakan untuk menguji model dan hipotesis mengestimasikannya menggunakan LISREL Hasil penelitian diperoleh bahwa kepemimpinan, motivasi, kepuasan kerja, berpengaruh secara positif dan signifikan terhadap komitmen organisasi secara parsial maupun bersama-sama dengan konstribusi sebesar $60 \%$, varabel yang mendominasi yaitu variabel motivasi dengan koefisien setandat sebesar 0,44 dimensi yang merefleksiikan motivasi kerja adalah kebutuhan akan kekuasaan sebesar 0,85 , sedangkan variabel yang merefleksikan komitmen dosen adalah komitmen normatitif sebesar 0,83 peneliti merekomendasikan bawa komitmen dosen dapat ditingkatkan terutama melalui motivasi kerja dosen melalui dimensi kebutuhan kekuasaan pada PTS Kota dan kabupaten Serang
\end{abstract}

Kata kunci: Komitmen organisasi , kepemimpinan, motivasi, kepuasan kerja,.

Organizational commitment in higher education influences the quality and carrying capacity of the sustainability of an organization, in this case many analyzes are developed to measure organizational commitment, but not many discuss the model of the organization's own commitment to the sustainability of an organization that oversees the lecturer. This research was conducted as an effort to measure the commitment of organizations to support the sustainability of universities. A (PTS), the lecturer commitment assessment model was developed to see whether the commitment of lecturers had an influence on the sustainability of universities. The research method used was descriptive and verification of data samples of 275 PTS lecturers of City and Regency, Application of Structural Equation Model (SEM) was used to test models and hypotheses estimated using LISREL The results showed that leadership, motivation, job satisfaction, had a positive and significant effect to organizational commitment partially or jointly with a contribution of $60 \%$, the dominating varabel is the motivation variable with a 0.44 dimension sign coefficient reflecting work motivation is the need for power of 0.85 , while the variable that reflects the commitment of the lecturer is commitment normative as much as 0.83 researchers recommend that lecturer commitment can be increased especially through the work motivation of lecturers through the dimensions of power needs in PTS Serang City and regency. 
Keywords: Organizational commitment, leadership, motivation, job satisfaction ,.

\section{PENDAHULUAN}

Komitmen dosen bagi sebuah perguruan tinggi sangatlah penting untuk keberlanjutan pengembangan perguruan tinggi karena Komitmen organisasional menurut Luthans (2006:249) adalah sikap loyalitas karyawan proses berkelanjutan dari seorang anggota organisasi mengekspresikan perhatian mereka kepada kesuksesan dan kebaikan organisasinya. Sikap loyalitas ini diindikasikan melalui tiga hal, yaitu: keinginan kuat seseorang untuk tetap menjadi anggota organisasinya; kemauan untuk mengerahkan usahanya untuk organisasinya; keyakinan dan penerimaan yang kuat terhadap nilai nilai dan tujuan organisasi. Komitmen organisasional akan membuat pekerja memberikan yang terbaik kepada organisasi nya . Pekerja yang memiliki komitmen yang tinggi akan lebih berorientasi pada kerja akan cenderung senang membantu dan dapat bekerjasama

Agar perilaku dan komitmen organisasional para dosen baik, maka keefektifan peran seorang pemimpin ,Pendidikan tinggi sangatlah diperlukan .Untuk menjadi pemimpin yang efektif, seorang pimpinan universitas harus dapat mempengaruhi seluruh civitas akademika yang dipimpinnya melalui cara cara yang positif untuk mencapai tujuan pendidikan di PTS. Melalui dosen yang memiliki motivasi dan memiliki kepuasan kerja tinggi demi kemajuan dan keberlajutan Perguruan Tinggi Suasta (PTS) di Kota dan Kabupaten Serang

\section{TUJUAN PENELITIAN}

Berdasarkan permasalahan di atas, tujuan yang hendak dicapai melalui penelitian ini adalah untuk menguji besarnya:

1. Pengaruh kepemimpinan terhadap Komitmen Organisasi Pada Perguruan Tinggi Swasta (PTS) di Kota dan Kabupaten Serang.

2. Pengaruh motivasi terhadap Komitmen Organisasi Pada Perguruan Tinggi Swasta (PTS) di Kota dan Kabupaten Serang.

3. Pengaruh kepuasan kerja terhadap Komitmen Organisasi Pada Perguruan Tinggi Swasta (PTS) di Kota dan Kabupaten Serang.

4. Pengaruh kepemimpinan, motivasi, dan kepuasan kerja, secara bersama-sama terhadap Komitmen Organisasi pada Perguruan Tinggi Swasta (PTS) di Kota dan Kabupaten Serang.

\section{LANDASAN TEORI}

\section{Teori Kepemimpinan}

Pemimpin hakikatnya adalah seorang yang mempunyai kemampuan untuk mempengaruhi perilaku orang lain di dalam kerjanya dengan menggunakan kekuasaan (Daft, 2005) untuk mempengaruhi, mengarahkan, memberi petunjuk, memotivasi, mengispirasi, membangkitkan kekuatan, memberi perintah kepada orang lain atau kelompok untuk mendukung, merespon, menggunakan, melakukan sesuatu, membuat 
orang lain bertindak, melalui komunikasi untuk melakukan perubahan budaya organisasi yang lebih maju dalam rangka mencapai hasil nyata dan tujuan bersama (Ivancevich dkk., 2002).

Ada tiga dimensi variabel kepemimpinan secara umum yang berlaku dalam dunia organisasi (Fred E. Fiedler dalam Ivancevich dkk, 2002: 433), yaitu :

1). Hubungan antara pemimpin dengan bawahan (X1.1). Terdiri atas sub dimensi :kemampuan menghormati hak dan kewajiban setiap pegawai; komunikasi yang hangat antara pimpinan dengan pegawai; membantu memecahkan persoalan pegawai; menghargai hasil kerja bawahan; dan bersikap objektif pada bawahan.

2). Struktur tugas (X1.2), terdiri atas sub dimensi : kesederhanaan rencana kerja yang dapat disosialisasikan; realisasi rencana kerja; dan kejelasan tanggung jawab atas pekerjaan.

3). Kekuasaan (X1.3), terdiri atas sub dimensi : kemampuan memerintah bawahan; ketegasan dalam mengambil keputusan; dan mengembangkan kualitas bawahan.

\section{Motivasi Kerja}

Motivasi kerja adalah kesediaan untuk mengeluarkan tingkat upaya yang tinggi ke arah tujuan-tujuan organisasi, yang dikondisikan oleh kemampuannya untuk yang menguatkan perilaku, memberikan arah bertindak, dan pemicu untuk tetap terus berusaha dalam rangka menghasilkan kinerja dan penghargaan atas hasil yang diinginkan dan upaya memenuhi suatu kebutuhan individual (Robbins dan Judge, 2008). McClelland menyatakan bawah motivasi kerja memiliki tiga buah dimensi penting (Ivancevich dkk 2002:159) yaitu :

1). Kebutuhan untuk berprestasi (X2.1), yang terdiri atas sub dimensi : upaya untuk berprestasi baik; upaya untuk tidak ketinggalan oleh pegawai lain; upaya mengembangkan diri; dan upaya untuk mendapatkan pengakuan dari hasil kerja.

2). Kebutuhan untuk berafiliasi (X2.2), yang terdiri atas sub dimensi : semangat untuk berafiliasi dengan lingkungannya; semangat untuk dapat bekerjasama; semangat mematuhi segala aturan yang ada dan selalu menghormati pimpinan

3). Kebutuhan untuk kekuasaan (X2.3), yang terdiri atas sub dimensi : berusaha agar dirinya di hargai; upaya untuk tidak diremehkan; dan kehadiran sangat diperlukan orang lain.

\section{Kepuasan Kerja}

Kepuasan kerja adalah sikap umum atau sikap positif terhadap pekerjaan yang timbul berdasarkan penilaian terhadap situasi kerja atau membandingkan antara banyaknya ganjaran yang diterima dengan yang mereka harapkan atau ekspektasikan atau persepsikan. Robbins dan Judge (2008) menyatakan bahwa, Kepuasan kerja adalah suatu sikap umum terhadap pekerjaan seseorang, selisih antara banyaknya ganjaran yang diterima seorang pekerja dan banyaknya ganjaran yang mereka yakini seharusnya mereka terima. Kepuasan kerja biasanya terbentuk atas tiga variabel utama, yaitu : 
1). Hubungan kerja (X3.1), terdiri atas sub variabel : keharmonisan dalam berinteraksi dengan atasan; komunikasi dua arah; kerjasama antar dosen;, dan keterbukaan dan transparansi.

2). Tantangan kerja (X3.2), terdiri atas sub variabel: menyelesaikan tugas; kepuasan dalam menyelesaikan tugas; tanggung jawab; disiplin; dan keterampilan mengambil keputusan.

3). Perlindungan kerja (X3.3), terdiri atas sub variabel: perlindungan dari Pemerintah; perlindungan dari perjanjian kerja; dan perlindungan dari asuransi.

\section{Komitmen Organisasi}

Wieneer mendefinisikan komitmen sebagai bentuk totalitas keyakinan normative untuk melakukan aksi di mana ada titik temu antara tujuan organisasi dan interest, dan individu memutuskan untuk berperilaku karena mereka percaya bahwa hal itu benar dan sesuai dengan moral (Meyer dan Allen, 2001: 66). Komitmen organisasi adalah sikap kerja, emosi, keyakinan, kerelaan yang mencerminkan hasrat, kebutuhan, tanggung jawab, keberpihakan dan keterlibatan untuk bekerja keras, keinginan yang pasti untuk bertahan dalam organisasi dan memberikan usaha yang terbaik, energi serta waktu untuk sebuah pekerjaan atau aktivitas.

Meyer dan Allen (2001:64) mengelompokan komitmen organisasi ke dalam tiga aspek yaitu :

1). Komitmen afektif (Y1), yang memuat aspek kepercayaan yang kuat dan menerima nilai dan tujuan organisasi; loyalitas terhadap organisasi; dan kerelaan menggunakan upaya demi kepentingan organisasi.

2). Komitmen kontinyu (Y2), memuat aspek memperhitungkan keuntungan untuk tetap bekerja dalam organisasi; dan memperhitungkan kerugian jika meninggalkan organisasi.

3). Komitmen normatif (Y), memuat aspek kemauan bekerja; dan tanggung jawab memajukan organisasi.

\section{Hipotesis Penelitian}

Untuk mendukung model yang dikembangkan dalam penelitian ini, maka diajukan lima buah hipotesis sebagai berikut :

1). H-1 Apakah kepemimpinan berpengaruh terhadap Komitmen dosen Pada PTS Kota dan Kabupaten Serang

2). H-2:Apakah Motivasi Kerja berpengaruh terhadap Komietmen dosen Pada PTS Kota dan Kabupaten Serang

3). H-3:Apakah kepuasan kerja berpengaruh terhadap Komietmen dosen Pada PTS Kota dan Kabupaten Serang

4). H-4: Apakah kepemimpinan, motivasi, kepuasan kerja secara simultan berpengaruh terhadap dan komitmen organisasi Pada PTS Kota dan Kabupaten Serang

\section{Metodoe Penelitian}


Penelitian ini dilakukan melalui beberapa tahap yaitu, pertama, tahap Konseptual difokuskan pada upaya untuk merumuskan dan membatasi masalah, meninjau kepustakaan yang relevan, mendefinisikan kerangka teoritis, merumuskan hipotesis. Kedua, tahap Perancangan dan perencanaan yang memuat aktifitas berupa memilih rancangan penelitian, mengidentifikasi populasi yang diteliti, mengkhususkan metode untuk mengukur variabel penelitian, merancang rencana sampling, mengakhiri dan meninjau rencana penelitian, melaksanakan pilot penelitian dan membuat revisi. Ketiga, mendisain instrumen pengumpulan data penelitian dan model peningkatan kinerja dosen dalam rangka meningkatkan kinerja organisasi secara berkelanjutan, keempat, tahap empirik dimana pada tahap ini dilakukan pengumpulan data dan penyiapan data untuk analisis; dan kelima adalah tahap analitik yang memuat kegiatan analisis data dan interpretasi hasil serta pengujian terhadap hipotesis yang telah disusun. Diagram alur penelitian seperti diperlihatkan pada Gambar 1. Rancangan model peningkatan kinerja dosen perguruan tinggi swasta yang diusulkan dalam penelitian ini seperti diperlihatkan pada Gambar 2.

Menentukan research
problem, batasan dan

literature review

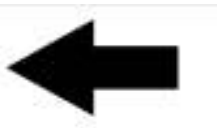

Conceptual Fase

Menentukan populasi. sampling, pengukuran sample

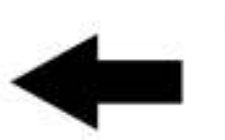

Research design and Planning

Merancang instrumen
penelitian dan model penelitian dan model
yang dikembangkan
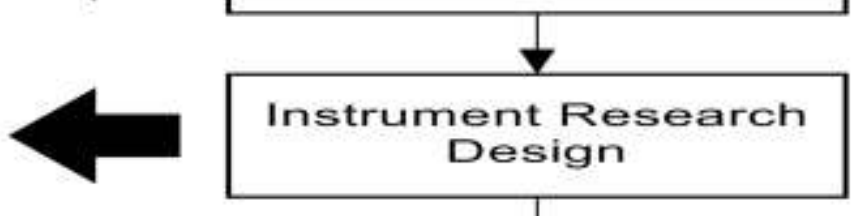

Pengumpulan dan penyiapan data untuk
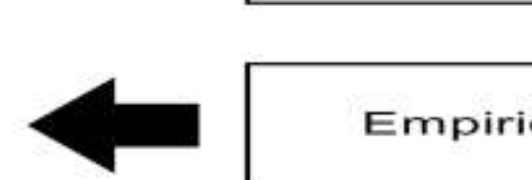

$$
\begin{aligned}
& \text { analisis } \\
& \text { Analisis data hasil } \\
& \text { persepsi tanggapan } \\
& \text { responden }
\end{aligned}
$$

Interpretasi hasil analisis dan pengujian

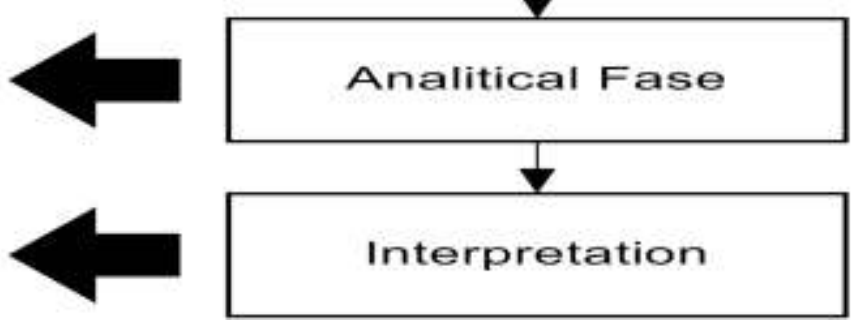

Empirical Fase

Gambar 1. Alur penelitian

Tabel 1 : Total Populasi dan Sempel

\begin{tabular}{|c|l|c|c|}
\hline NO & NAMA PT & $\begin{array}{c}\text { POPULA } \\
\text { SI }\end{array}$ & $\begin{array}{c}\text { SAMPE } \\
\text { L }\end{array}$ \\
\hline 1 & UNSERA & 133 & 76 \\
\hline 2 & UNBAJA & 19 & 11 \\
\hline 3 & STIA MAULANA YUSUF & 13 & 7 \\
\hline 4 & STIKES FALETEHAN & 46 & 26 \\
\hline
\end{tabular}




\begin{tabular}{|c|l|c|c|}
\hline NO & \multicolumn{1}{|c|}{ NAMA PT } & $\begin{array}{c}\text { POPULA } \\
\text { SI }\end{array}$ & $\begin{array}{c}\text { SAMPE } \\
\text { L }\end{array}$ \\
\hline 5 & STT FATAHILLAH & 31 & 18 \\
\hline 6 & STIKOM WANGSA JAYA & 4 & 2 \\
\hline 7 & STIE BANTEN & 35 & 20 \\
\hline 8 & STKIP BANTEN & 0 & 0 \\
\hline 9 & STIE BINA BANGSA & 56 & 32 \\
\hline 10 & STIM PRIMA GRAHA & 27 & 15 \\
\hline 11 & STMIK MUHAMADIAH BANTEN & 9 & 5 \\
\hline 12 & STISIP GUNA NUSANTARA & 0 & 0 \\
\hline 13 & STIE DWIMULYA & 14 & 8 \\
\hline 14 & AMIK SERANG & 6 & 3 \\
\hline 15 & AKADEMI TELEKOMUNIKASI NUSANTARA & 4 & 2 \\
\hline 16 & AKADEMI KEBIDANAN AISYIYAH & 14 & 8 \\
\hline 17 & AKADEMI KEBIDANAN BHAKTI PURNA HUSADA & 8 & 5 \\
\hline 18 & AKADEMI KEBIDANAN BINA HUSADA & 9 & 5 \\
\hline 19 & AKADEMI AKUNTANSI KEUANGAN PERBANKAN & 12 & 7 \\
\hline 20 & INDONESIA & 25 & 14 \\
\hline 21 & POLITEKNIK PIKSI INFUT & 18 & 10 \\
\hline & POLITEKNIK BANTEN & $\mathbf{4 8 3}$ & $\mathbf{2 7 5}$ \\
\hline
\end{tabular}

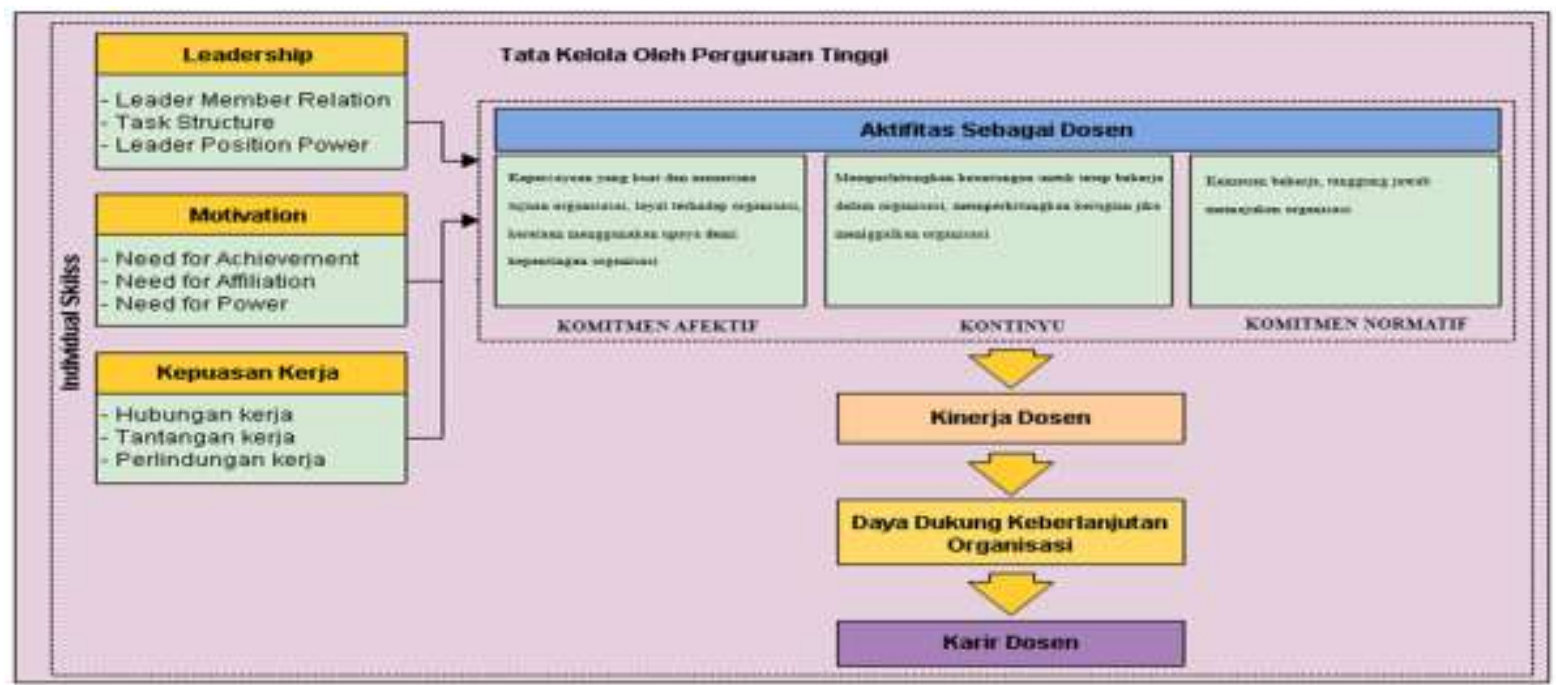

Gambar 2. Usulan model peningkatan Komitmen Organisasi

\section{HASIL DAN PEMBAHASAN}

\section{1) Uji Validitas dan Uji Reabilitas}

Berdasar Hasil uji validitas memperlihatkan bahwa nilai-nilai koefisien atau $r$ hitung untuk setiap variabel lebih besar dari nilai $r$ product momennya, dengan demikian dapat dikatakan bahwa seluruh instrumen dalam penelitian ini bernilai valid. Hasil uji validitas instrumen penelitian seperti diperlihatkan pada Gambar 3. 


\begin{tabular}{|l|c|c|c|c|c|c|c|c|c|c|c|c|}
\hline R hitung & 0.31 & 0.31 & 0.31 & 0.31 & 0.31 & 0.31 & 0.31 & 0.31 & 0.31 & 0.31 & 0.31 & 0.31 \\
\hline KP & 0.67 & 0.53 & 0.74 & 0.70 & 0.76 & 0.80 & 0.84 & 0.75 & 0.80 & 0.63 & & \\
\hline MK & 0.60 & 0.69 & 0.74 & 0.66 & 0.66 & 0.71 & 0.63 & 0.62 & 0.63 & 0.62 & 0.48 & \\
\hline KK & 0.60 & 0.59 & 0.63 & 0.71 & 0.81 & 0.63 & 0.73 & 0.76 & 0.81 & 0.76 & 0.80 & 0.73 \\
\hline KO & 0.62 & 0.44 & 0.58 & 0.52 & 0.58 & 0.70 & 0.61 & & & & & \\
\hline
\end{tabular}

Sumber : Data Primer diolah SPSS 22

Gambar 3. Hasil uji validitas instrumen penelitian

Uji reliabilitas dilakukan dengan menghitung koefisien Cronbach Alpha dari masing-masing item dalam suatu variabel. Instrumen yang dipakai dalam variabel tersebut dikatakan reliabel bila nilai Cronbach Alpha lebih dari 0.6 (Nunnaly dalam Ghozali, 2002). Hasil pengujian reliabilitas memperlihatkan bahwa instrumen kepemimpinan, memiliki nilai koefisien Alpha-Cronbach sebesar 0.915; motivasi kerja sebesar 0.856; kepuasan kerja sebesar 0,912; komitmen organisasi sebesar 0,652. . Hal pengujian reliabilitas menunjukkan bahwa seluruh instrumen pada variabel penelitian sangat reliable.

\section{2) Analisis Deskriptif}

\section{a. Kepemimpinan (X1)}

Variabel kepemimpinan di ukur dengan tiga dimensi yaitu hubungan kerja antara pimpinan dengan pegawai (X1.1) menggunakan lima pertanyaan, struktur tugas terhadap kepemimpinan (X1.2) menggunakan tiga pertanyaan, dan kekuasaan posisi (X1.3) menggunakan tiga pertanyaan. Hasil penilaian persepsi terhadap tanggapan responden diperoleh skor rata-rata sebesar 3.933. Hasil persepsi ini dapat dikelompokan ke dalam kategori baik. Indikator yang memiliki nilai tertinggi berdasarkan tanggapan responden adalah indikator komunikasi yang hangat antara pimpinan dengan pegawai sebesar 4.280, sedangkan indikator dengan nilai skor terendah diperlihatkan pada indikator menghargai hasil kerja bawahan sebesar 3.615. Berdasarkan hasil penilaian persepsi tanggapan respeonden dapat disimpulkan bahwa indikator kepemimpinan secara umum dikategorikan baik untuk digunakan sebagai alat ukur kinerja dosen.

\section{b. Motivasi Kerja (X2)}

Variabel motivasi kerja diukur dengan tiga dimensi yaitu kebutuhan berprestasi (X2.1) menggunakan empat pertanyaan, kebutuhan berafiliasi (X2.2) menggunakan empat pertanyaan dan kebutuhan kekuasaan (X2.3) menggunakan tiga pertanyaan. Hasil pengukuran terhadap persepsi tanggapan responden diperoleh bawah variabel motivasi kerja memiliki skor rata-rata 4.258 dan dikelompokan ke dalam kategori mendekati baik. Skor indikator tertinggi pada variabel ini ditunjukan oleh indikator berusaha untuk menjaga persahabatan dengan teman sekerja dengan rata-rata skor persepsi sebesar 4.360, sedangkan skor indikator terendah diperlihatkan oleh indikator upaya untuk mendapatkan pengakuan dari hasil kerja sebesar 3.735. Berdasarkan hasil penilaian persepsi tanggapan respeonden dapat disimpulkan bahwa indikator kepemimpinan secara umum dikategorikan baik untuk digunakan sebagai alat ukur kinerja dosen. 


\section{c. Kepuasan Kerja (X3)}

Variabel kepuasan kerja diukur dengan tiga dimensi yaitu hubungan kerja (X3.1) menggunakan empat pertanyaan, tantangan kerja (X3.2) menggunakan lima pertanyaan dan dimensi perlindungan kerja (X3.3) menggunakan tiga pertanyaan. Hasil pengukuran terhadap persepsi tanggapan responden variabel kepuasan kerja memiliki skor rata-rata 3.856 dan dikelompokan ke dalam kategori mendekati baik. Indikator dengan skor tertinggi ditunjukan oleh indikator komunikasi dua arah sebesar 3.962, sedangkan skor persepsi terendah diperlihatkan oleh indikator perlindungan dari asuransi sebesar 3.303. Berdasarkan hasil penilaian persepsi tanggapan respeonden dapat disimpulkan bahwa indikator kepemimpinan secara umum dikategorikan baik untuk digunakan sebagai alat ukur kinerja dosen..

\section{d. Komitmen Organisasi (Y)}

Komitmen organisasi diukur melalui dimensi komitmen afektif (Y1), komitmen kontinyu (Y2), dan komitmen normatif (Y3). Varibale ini secara keseluruhan menggunakan tujuh pertanyaan untuk melihat persepsi tanggapan responden. Skor persepsi tanggapan responden terhadap tujuh item pertanyaan yang diajukan menunjukkan bahwa keseluruhan dimensi memiliki rata-rata sebesar 4.037 atau dikategorikan pada level tinggi. Skor tertinggi sub dimensi X4.3 yakni indikator tanggung jawab memajukan organisasi (komitmen normatif) sebesar 4.145, sedangkan skor terendah diperlihatkan pada item dimensi X4.1 yakni indikator loyalitas terhadap organisasi (komitmen afektif) sebesar 3.680. Hasil persepsi tanggapan responden ini memperlihatkan bahwa dari ketiga dimensi yang digunakan, dimensi komitmen normatif sub dimensi tanggung jawab memajukan organisasi merupakan indikator komitmen organisasi tertinggi sebesar 4.129, disusul komitmen kontinyu sebesar 4.040 dan terendah pada komitmen afektif sebesar 3.888 .

\section{3) Analisis data, Stuktural dan hasil hipotesis}

Selanjutnya dilakukan analisis data yang dihasilkan melalui penerapan model komitmen organisasi jumlah sampel 275 dosen dari berbagai dosen di PTS dan hasil penyebaran angket tentang aktivitas sebagai dosen melalui pengembangan model kepemimpinan, motivasi, kepuasan kerja dan komitmen organisasi dengan mengunakan program Lisrel (SEM) dapat diketahui berbagai tingkat koefisien regresi dari setiap variabel adalah sebagai berikut, Gambar 4: 


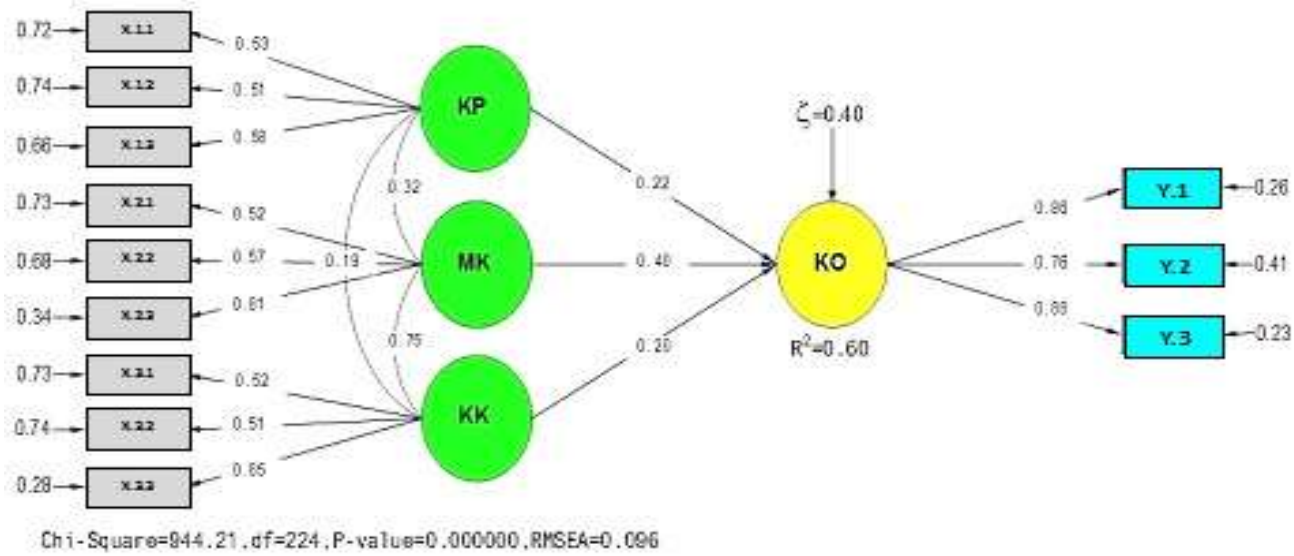

Sumber: Output hasil pengolahan lisrel

Gambar 4 : Diagram Jalur Model Persamaan Struktural

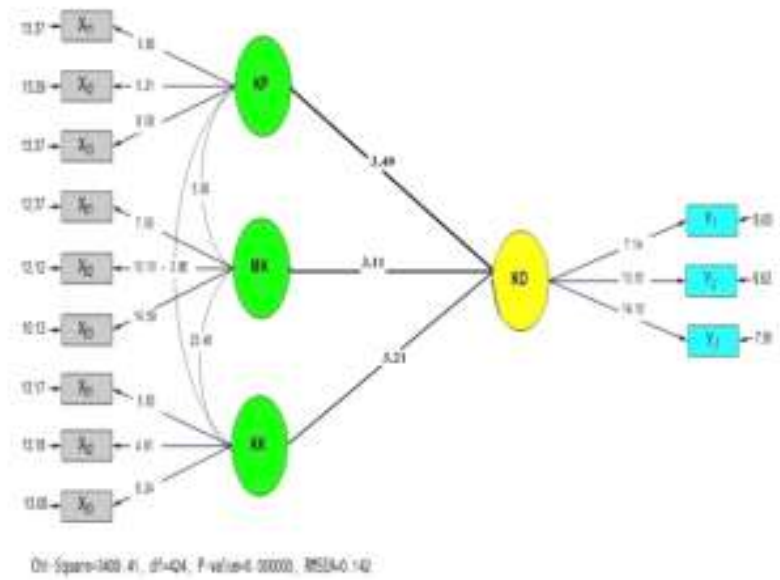

Gambar 5. Nilai t Value dengan mengunakan model SEM

Berdasarkan output lisrel atau nilai koefisien regresi dapat di ketahui bahwa seluruh dimensi pada indikator valid karena memiliki nilai loading factor $>0.05$ sedangkan output lisrel pada $t$ value seluruhnya signifikan karena nilai $t$ hitung $>1.96$ maka dapat disimpulkan bahwa model ini memiliki Goodnes of fit yang cukup baik, sehingga data yang ada dapat dilakukan untuk analisis selanjutnya (pengujian hipotesis)

Berdasarkan dari kedua model tersebut Hasil pengolahan uji kesesuaian dan statistik memperlihatkan bahwa :

\section{H-1 Apakah kepemimpinan berpengaruh terhadap Komitmen Organisasi}

Nilai koefisien standard sebesar 0,22 dan nilai t hitung lebih besar t tabel ( 3,40> 1,96) Dengan demikian dapat disimpulkan, dimensi-dimensi kepemimpinan (KP) memiliki pengaruh positif dan signifikan terhadap komitmen organisasi (KO). Dengan kata lain, model parsial H1 untuk hipotesis ke-1 ini diterima,. Dapat dinyatakan bahwa semakin baik Kepemimpinan, maka akan berimplikasi semakin tingginya komitmen organisasi.

Melalui standardized loding factor (SLF) diketahui bahwa dari 3 (tiga) dimedensi, dimensi kekuasaan posisi (leader position power) (X.1.3), merupakan dimensi terkuat 
yang menjelaskan komitmen organisasi yaitu 0,57 Dimensi kedua adalah dimensi hubungan kerja antara pimpinan dengan dosen (leader member relation) (X.1.1) adalah sebesar 0,53 dan dimensi yang terendah struktur tugas terhadap kepemimpinan (task structur) (X.1.2) adalah sebesar 0,52 dari hasil ini dapat dinyatakan bahwa dimensi kekuasaan posisi merupakan dimensi yang paling refresentatif untuk diterapkan dalam upaya meningkatkan komitmen organisasi Perguruan Tinggi Swasta ( PTS) di Kota dan Kabupaten Serang. Hasil penelitian ini menguatkan hasil temuan Lumbanraya (2009) yang menyimpulkan bahwa kepemimpinan berpengaruh langsung terhadap komitmen pegawai., Galanou Ekaterini (2010) yang menyimpulkan bahwa kepemimpinan mempengaruhi komitmen. Dan temuan $\mathrm{Wu}$, et.al., 2006 yang menyimpulkan bahwa kepemimpinan mempengaruhi komitmen organisasi.

\section{H-2:Apakah Motivasi Kerja berpengaruh terhadap Komitmen Organisasi}

Hasil nilai koefisien standard sebesar 0,40, dengan nilai t hitung lebih besar dari t $(3,11>$. 1,96). Dengan demikian dapat disimpulkan, dimensi-dimensi motivasi kerja (MK) memiliki pengaruh positif dan signifikan terhadap komitmen organisasi. Dengan kata lain, hipotesis ke-2 ini diterima.Dapat dinyatakan bahwa semakin baik motivasi kerja, maka akan berimplikasi semakin tingginya komitmen organisasi.

Melalui standardized loding faktor (SLF) diketahui bahwa dari 3 (tiga) dimensi, Dimensi kebutuhan berprestasi, kebutuhan berafiliasi dan kebutuhan kekuasaan. Berikut estimasi parameter variabel motivasi kerja: dimensi kebutuhan kekuasaan (X.2.3) merupakan dimensi terkuat yang menjelaskan komitmen organisasi sebesar 0,85. Dimensi kedua adalah kebutuhan berafiliasi (X.2.2) adalah sebesar 0,58, dan dimensi yang terendah dimensi kebutuhan berprestasi (X.2.1) sebesar 0,57, dari hasil ini dapat dinyatakan bahwa dimensi kebutuhan kekuasaan posisi merupakan dimensi yang paling refresentatif untuk diterapkan dalam upaya meningkatkan komitmen organisasi Perguruan Tinggi Swasta ( PTS) di Kota dan Kabupaten Serang. Hasil penelitian ini menguatkan temuan YuenOnn, dan Kee-Luen Wong (2011) yang menyimpulkan bahwa, motivasi instrinsik berpengaruh signifikan terhadap komitmen organisasi, terutama pada aspek afeksi, continuance, dan normatif. Dan Bhatti, et.al, (2011), yang menyimpulkan bahwa, motivasi mempunyai pengaruh signifikan terhadap komitmen organisasi, komitmen organisasi sangat dipengaruhi oleh motivasi karyawan, karyawan yang mempunyai motivasi tinggi akan mempunyai komitmen yang tinggi dan sebaliknya.

\section{H-3:Apakah kepuasan kerja berpengaruh terhadap Komitmen Organisasi}

Nilai koefisien standard sebesar 0,20, sedangkan $\mathrm{t}$ hitung lebih besar $\mathrm{t}$ tabel (3,21>. 1,96. Dengan demikian dapat disimpulkan, dimensi-dimensi kepuasan kerja (KK) memiliki pengaruh positif dan signifikan terhadap komitmen organisasi (KO). . Dengan kata lain, model parsial H1 untuk hipotesis ke--3 ini diterima. Artinya semakin naik kepuasan dosen, maka akan berimplikasi semakin tingginya komitmen organisasi.

Melalui standardized loding faktor (SLF) diketahui bahwa dari 3 (tiga) dimensi, dimensi hubungan kerja, tantangan kerja, dimensi perlindungan kerja (X.3.3) merupakan dimensi terkuat yang menjelaskan komitmen organisasi sebesar 0,58. Dimensi kedua adalah dimensi tantangan kerja (X.3.2) adalah sebesar 0,57, dan dimensi yang terendah dimensi hubungan kerja (X.3.1), adalah sebesar 0,52, dari hasil ini dapat dinyatakan 
bahwa dimensi perlindungan kerja merupakan dimensi yang paling representatif untuk diterapkan dalam upaya meningkatkan komitmen organisasi Perguruan Tinggi Swasta ( PTS) di Kota dan Kabupaten Serang. Hasil penelitian ini menguatkan temuan Garbarino dan Johnson (2009) yang menyimpulkan bahwa semakin tinggi tingkat kepuasan karyawan semakin tinggi pula komitmen karyawan terhadap perusahaan. Dan Ahmad, Ahmad, dan Shah, (2010), yang menyimpulkan bahwa ada pengaruh langsung yang kuat dan positif antara kepuasan kerja dengan komitmen organisasi serta temuan Sabir, Sohail, Khan, (2011) yang menyimpulkan bahwa kepuasan kerja dapat mempengaruhi komitmen organisasi

\section{H-4: Apakah Pengaruh Kepemimpinan, motivasi dan kepuasan kerja Terhadap Komitmen Organisasi}

Nilai standard estimate adalah sebagai berikut: $\mathrm{KO}=0.22 * \mathrm{KP}+0.40 * \mathrm{MK}+$ $0.20 * \mathrm{KK}, \mathrm{R} 2=0.60$. Sedangkan diperoleh nilai $\mathrm{F}$ hitung $>\mathrm{F}$ tabel $(135,50>2.605)$, maka model simultan H1 untuk hipotesis ke-4 ini diterima, mengandung makna bahwa variasi komitmen organisasi mampu dijelaskan oleh kepemimpinan, motivasi, dan kepuasan kerja sebesar $60 \%$, dan sisanya $40 \%$ dipengaruh faktor lain yang tidak diteliti dalam model. Faktor lain dimaksud antara lain, gaji, tunjangan, lingkungan kerja atau kenyamanan kerja, dan lainnya.

Melalui perbandingan ini diketahui dari dua eksogen yang digunakan, komponen motivasi kerja merupakan variabel motivasi yang dominan menjelaskan komitmen organisasi dengan standardized coefficient sebesar 0.40, kemudian kepemimpinan dengan standardized coefficient sebesar 0,22, serta kepuasan kerja dengan standardized coefficient sebesar 0,20.

Hasil penelitian ini menunjukkan bahwa kepemimpinan, motivasi kerja dan kepuasan kerja secara bersama-sama berpengaruh signifikan terhadap komitmen organisasi. Hubungan ini dapat diinterprestasikan bahwa perubahan komitmen organisasi dipengaruhi oleh variabel kepemimpinan, motivasi kerja dan kepuasan kerja,dengan kata lain, model simultan untuk hipotesis ke-4 ini diterima. Hasil penelitian ini menguatkan hasil penelitian Afifah (2011) yang menyimpulkan bahwa terdapat hubungan yang signifikan antara kepemimpinan, motivasi kerja, dan kepuasan kerja secara bersama-sama terhadap komitmen organisasi.

\section{KESIMPULAN DAN SARA}

\section{1). Kesimpulan}

Berdasarkan penelitian yang dilakukan, maka dapat ditarik kesimpulan sebagai berikut :

1. Kepemimpinan berpengaruh positif dan signifikan terhadap komitmen organisasi, terutama dimensi komitmen normative yang merefleksi menjelaskan komitmen organisasi, sedangkan dimensi kekuasaan posisi yang merefleksi menjelaskan kepemimpinan, dengan demikian untuk meningkatkan variabel komitmen organisasi terutama dimensi komitmen normative, perlu memperhatikan variabel kepemimpinan terutama dimensi kekuasaan posisi, melalui indikator pimpinan selalu berusaha meningkatkan kemampuan dalam memerintah bawahan, dan ketegasan dalam mengambil keputusan serta selalu mengembangkan kualitas bawahan. Hal ini 
menunjukkan bahwa kemampuan kepemimpinan yang lebih baik akan berimplikasi pada semakin tingginya peningkatan komitmen organisasi. pada PTS di Kota dan Kabupaten Serang.

2. Motivasi kerja berpengaruh positif dan signifikan terhadap komitmen organisasi, terutama dimensi komitmen normative yang merefleksi menjelaskan variabel komitmen organisasi, sedangkan dimensi kebutuhan kekuasaan yang merefleksi menjelaskan motivasi kerja. Dengan demikian untuk meningkatkan variabel komitmen organisasi terutama dimensi komitmen normative perlu memperhatikan variabel motivasi kerja terutama dimensi kebutuhan kekuasaan, melalui indikator dosen berusaha agar dirinya dapat dihargai, dan berupaya untuk tidak diremehkan dan kehadiran sangat diperlukan orang lain. hal ini menunjukkan bahwa perbaikan motivasi kerja akan berimplikasi pada semakin tingginya peningkatan komitmen organisasi pada PTS Kota dan Kabupaten Serang.

3. Kepuasan kerja memiliki pengaruh positif dan signifikan terhadap komitmen organisasi, terutama dimensi komitmen normative yang merefleksi menjelaskan variabel komitmen organisasi, sedangkan dimensi perlindungan kerja yang merefleksi menjelaskan variabel kepuasan kerja, dengan demikian untuk meningkatkan variabel komitmen organisasi terutama dimensi komitmen normatif perlu memperhatikan variabel kepuasan kerja terutama dimensi perlindungan kerja, melalui indikator pimpinan harus berupaya agar dosen mendapatkan perlindungan dari Pemerintah, Institusi dan Asuransi, Hal ini menunjukkan bahwa perbaikan kepuasan kerja berimplikasi pada semakin tingginya peningkatan komitmen organisasi pada PTS di Kota dan Kabupaten Serang .

4. Kepemimpinan, motivasi dan kepuasan kerja secara simultan berpengaruh positif dan signifikan terhadap komitmen organisasi dengan konstribusi sebesar enam puluh persen, sementara sisanya dipengaruhi variabel lain yang tidak diteliti. Adapun variabel yang paling mendominasi menjelaskan variabel komitmen organisasi adalah variabel motivasi kerja, dengan demikian untuk meningkatkan variabel komitmen organisasi terutama dimensi komitmen normative, melalui indikator pimpinan meningkatkan kemauan kerja keras dan rasa tangung-jawab dosen dalam menjalankan tugasnya, perlu memperhatikan variabel motivasi kerja terutama kebutuhan kekuasaan, melalui indikator agar dosen berusaha untuk dapat dihargai, tidak diremehkan dan kehadiran sangat diperlukan orang lain. Hal ini menunjukkan bahwa secara positif bahwa perbaikan dan peningkatan kepemimpinan, dan motivasi dan kepuasan kerja secara simultan akan berimplikasi pada meningkatnya komitmen organisasi pada PTS di Kota dan Kabupaten Serang.

\section{2) Saran}

Untuk menciptakan komitmen organisasi maka disarankan seluruh pimpinan PTS di kota dan kabupaten serang, untuk memperhatikan :

1. Motivasi kerja dosen terutama kebutuhan kekuasaan melalui peningkatan kualifikasi dosen, agar kedudukannya dapat dihargai, tidak diremehkan, dan kehadirannya sangat diperlukan 
orang lain, dan meningkatkan status kepegawaian dosen sebagai bentuk pengakuan dalam memenuhi dimensi kebutuhan berprestasi

2. Kepemimpin yang efektif dan efesien terutama kekuasaan posisi melalui pimpinan tegas dalam mengambil keputusan, mampu merancang kesederhanaan rencana kerja yang dapat disosialisasikan dan realisasikan untuk memenuhi struktur tugas dalam kepemimpinan, serta menciptakan hubungan yang harmonis dengan bawahan melalui sikap objektif, menghargai hasil kerja keras, membangun saling menghormati hak dan kewajiban dosen untuk memenuhi dimensi hubungan kerja antara pimpinan dengan pegawai

3. Kepuasan kerja dosen terutama perlindungan kerja baik dari pemerintah, institusi, dan asuransi dalam bentuk : perlindungan hukum, perlindungan profesi, serta perlindungan keselamatan dan kesehatan kerja serta tunjangan hari tua dosen, dengan demikian untuk meningkatkan komitmen organisasi perlu difokuskan pada komitmen normatif, yaitu kemauan kerja dan tanggung-jawab memajukan organisasi 


\section{DAFTAR PUSTAKA}

Afifah. 2011. Hubungan Kepemimpinan, Motivasi Kerja, dan Kepuasan Kerja terhadap Komitmen Organisasi Guru SMA dan SMK di Kabupaten Malang tahun 2011. Disertasi, Malang: Universitas Negeri Malang.

Ahmad, Habib; Khursheed Ahmad, dan Idrees Ali Shah, 2010, Relationship Between job Satisfaction, Job Performance Attitude Toward Work and Organizational commitment, European Journal of Social Sciences, Vol. 18, No. 2 pp 257-267.

Bhatti, Waheed Akbar, et.al., 2011, The Effect Motivation on Human Talent and Its Contribution to Organizational Performance, Management and Marketing Challenges for the Knowledge Society, Vol. 6 No. 3. Pp 471-482.

Daft, Richard L. 2005. The Leadership Experience, South Western: Venderbilt University. Garbarino dan Johnson, 2009, The Defferent Roles Of Satisfaction, Jurnal of Marketing Ghozali, Imam, 2002. Aplikasi Analisis Multivariate dengan Program SPSS, Universitas Diponegoro,Semarang.

Galanou. Ekaterini, 2010. The Impact of Leadership Styles on Four Variables of Executives Workforce. International Journal of Business and Management, 5 (6), pp : 3-16.

Hair, Joseph F.et. al. 2008. Multivariate Data Analysis. New Jersey: Prentice-Hall,Inc. Diunduh tanggal 25 September 2014 dari http://pdfcrop.in/ebook/title/hair-et-al2006-multivariate-data-analysis.htm

Ivancevich Michael T, Konopaske Robert, Matteson John M., 2002, Organizational Behavior and Management, seventh edition, Houston: McGraw Hill.

Lumbanraja, Prihatin, 2009, Pengaruh Karaketeristik Individu, Gaya Kepemimpinan, Budaya Organisasi terhadap Kepuasan Kerja dan Komitmen Organisasi (Studi pada Pemerintah Daerah di Provinsi Sumateria Utara), Jurnal Aplikasi Manajemen Vol 7 Nomor 2, Mei 2009. Pp 450-468.

Luthans, Fred (2002), Organizational Behavior, 7th ed, New York, McGraw-Hill.

Sabir Suleman M, Sohail Adill, dan Khan Muhammad Asif , 2011, Impact of Leadership Style on Organization Commitment: In Mediating Role of Employee Values, Journal of Economic and Behavioral Studies, Vol. 3 No. 2 pp 145-152.

Meyer, John P dan Natalie J Allen, 2001, A three Component Conceptualization of Organizational Commitment, Human Resource Management Review, Vol. 1 Number 1, 1991, p 61-89.

Robbins dan Judge. 2008. Perilaku Organisasi, Edisi Duabelas, Penerbit Salemba Empat: Jakarta

Wu, Tain-Fung, et.al., 2006, A Study of the Relationship between Manager's Leadership Style and Organizational Commitment in Taiwan's International Tourist Hotels, Asian Journal of Management and Humanity Science, Vol. 1, No. 3, pp. 434-452.

Yuen-Onn, Choong, dan Kee-Luen Wong, 2011, Intrinsic Motivation and Organizational Commitment in the Malaysian private higher education institutions: An Empirical Study, International refereed Research Journal, Vol. II, Issue 4, Oct 2011 pp 4050 . 